\title{
Voltaire, CEuvres de 1771
}

\section{Stefania Carli}

\section{(2) OpenEdition}

\section{Journals}

\section{Edizione digitale}

URL: http://journals.openedition.org/studifrancesi/30307

DOI: 10.4000/studifrancesi.30307

ISSN: 2427-5856

\section{Editore}

Rosenberg \& Sellier

\section{Edizione cartacea}

Data di pubblicazione: 1 avril 2006

Paginazione: 158

ISSN: 0039-2944

\section{Notizia bibliografica digitale}

Stefania Carli, «Voltaire, EFuvres de 1777», Studi Francesi [Online], 148 (XLX | I) | 2006, online dal 30

novembre 2015, consultato il 18 avril 2021. URL: http://journals.openedition.org/studifrancesi/30307 ; DOI: https://doi.org/10.4000/studifrancesi.30307

\section{Questo documento è stato generato automaticamente il 18 avril 2021.}

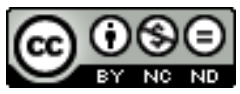

Studi Francesi è distribuita con Licenza Creative Commons Attribuzione - Non commerciale - Non opere derivate 4.0 Internazionale. 


\section{Voltaire, Euvres de 1771}

\section{Stefania Carli}

\section{NOTIZIA}

VoltAiRE, Cuvres de 1771, Oxford, Voltaire Foundation, 2004, («Les CEuvres complètes de Voltaire», 73), pp. XXI + 502.

1 Il volume presenta le opere composte da Voltaire nel 1771, anno interamente trascorso dall'autore a Ferney. Nella Préface, Nicholas Cronk ricorda come gli scritti qui riuniti siano essenzialmente di carattere politico: la situazione europea dell'epoca, così come quella della Francia continuano infatti ad interessare Voltaire, nonostante egli viva lontano da Parigi.

2 La prima opera che apre il volume è la tragedia Les Lois de Minos, che è stata spesso considerata dalla critica come una sorta di seconda edizione di Les Guèbres, testo che era apparso solo qualche anno prima, nel 1768. Come sottolinea Simon Davies nella sua accurata introduzione, si tratta di un'opera che, pur confermando la passione di Voltaire per il teatro, fu composta soprattutto per denunciare sia le atrocità legate ai cosiddetti "legal murders" del tempo, sia l'orrore del sacrificio umano. In realtà Les Lois de Minos, che risultano fondamentali anche per le numerose note di natura polemica che accompagnano il testo, rappresentano un chiaro riflesso delle vicissitudini politiche dell'epoca, in quanto vi si possono scorgere evidenti riferimenti alle situazioni di Svezia e Polonia.

3 Nella prima vera del 1771, Voltaire lavora poi ad una serie di pamphlets politici, in questo volume riuniti e presentati da Durand Echeverria. Sono nove brevi scritti composti dall'autore per sostenere il cancelliere René Nicolas de Maupeou, impegnato a quel tempo in un duro scontro contro i Parlamenti francesi; l'aperto sostegno di Voltaire isolò l'autore dagli altri philosophes, chiaramente schierati contro il cancelliere. Vengono dunque presentati l'Avis important d'un gentilhomme à toute la noblesse du Royaume; il Fragment d'une lettre écrite de Genève le 19 mars 1771, par un bourgeois de cette ville à un bourgeois de $L^{* * *}$; la Réponse aux remontrances de la Cour des aides, par un membre 
des nouveaux conseils souverains; i Sentiments de six conseils établis par le roi, et de tous les bons citoyens; le Très humbles et très respectueuses remontrances du grenier à sel, satira indicata da Echeverria come il pamphlet che ottenne più successo; la Lettre d'un jeune abbé; e poi ancora Les Peuples aux parlements, che al contrario degli altri scritti non contiene una chiara propaganda politica a favore del governo quanto piuttosto la presentazione delle idee personali di Voltaire, e infine L'Equivoque. Segue il Discours du conseiller Anne Du Bourg à ses juges, che fu pubblicato nell'autunno del 1771 e che fu composto dall'autore per ricordare e condannare l'intolleranza religiosa spesso dimostrata dal Parlamento di Parigi.

Dello stesso periodo è anche il Sermon du papa Nicolas Charisteski, testo che qui è curato da Michel Mervaud e che è rappresentativo dell'interesse manifestato da Voltaire per la situazione politica europea dell'epoca. Il Sermon è infatti incentrato sull'intervento russo in Polonia del 1768: il prete lituano ortodosso Nicolas Charisteski scongiura i "confédérés de Bar" di rompere l'alleanza con i turchi e di cessare gli scontri con i cristiani. Nel volume seguono poi due testi, entrambi presentati da Robert Granderoute, nei quali Voltaire affronta il problema della schiavitù: il primo è intitolato Coutume de Franche-Comté, sur l'esclavage imposé à des citoyens par une vieille coutume, e il secondo, indirizzato a Maupeou, Supplique des serfs de Saint-Claude à Monsieur le Chancelier.

Dopo La Méprise d'Arras, qui preceduta da un'introduzione di John Renwick e composta da Voltaire per difendere Monbailli e affrontare il problema della giustizia dell'epoca, sono riportati una serie di scritti che riguardano ancora i problemi di politica internazionale. Le Tocsin des rois, preceduto da una presentazione di Simon Davies, è un testo di propaganda che Voltaire scrisse su richiesta di Caterina II per sostenere i russi nella guerra contro la Turchia; l'Epitre au roi de Danemark, sempre curato da Simon Davies, è invece incentrata sul problema della libertà di stampa, libertà che il re di Danimarca aveva appena concesso su tutti i suoi territori, attirandosi in tal modo la simpatia di Voltaire; l'Epître à l'Impératrice de Russie, come sottolineano John Pappas e Andrew Kahn, riprende invece molti dei temi e dei problemi già affrontati dall'autore nella sua corrispondenza con l'imperatrice russa, come per esempio l'intolleranza dimostrata dai turchi, la speranza di rivedere presto Atene ritornare agli antichi splendori e il ruolo che il sovrano deve svolgere nella continua lotta contro l'ignoranza.

Come conclusione al volume, dopo l'Epître à M D'Alembert, curata e presentata, come la precedente, da John Pappas, che fa notare come vi si rifletta il contenuto dello scambio epistolare tra Voltaire e il suo discepolo risalente al biennio 1770-1771, sono inseriti tre brevi scritti riuniti da Simon Davies sotto il titolo di Shorter verse of 1771: si tratta dell'Epitre au roi de Suède dedicata a Gustavo III appena salito al trono dopo la morte del padre, della poesia Benaldaki à Caramouftée e dei versi A M. le Chancelier de Maupeou. La raccolta delle opere di Voltaire composte nel 1771, in un periodo storico in cui in Francia iniziano ad imporsi riforme e cambiamenti che lo stesso autore influenza con $\mathrm{i}$ propri scritti, termina infine con la lista dei Works cited e con l'indice generale. 